\title{
SOME ASPECTS OF SHEAR WALL DESIGN
}

\author{
T. PAULAY*
}

\section{INTRODUCTION}

The usefulness of certain walls in the structural planning of multistorey buildings in particular has long been recognised. When external or internal walls are situated in advantageous positions they can be very efficient in resisting lateral loads originat ing from wind or earthquakes. In addition to the potential strength, which shear walls possess, they offer considerable lateral stiffness and thus can protect a building against non-structural damage that arises when lateral displacement or sway becomes excessive during a moderate seismic disturbance.

Only in the last few years did the subject receive more attention and many aspects of the behaviour of shear walls are still being studied and evaluated. Because of necessary space Iimitations relevant features, which have been, treated in well known publications $(1,24)$, will be mentioned very briefly here, but reference to the appropriate source will be made. Other aspects, which are now understood a little better because of more recent research efforts, are presented in more detail. Emphasis is placed on features of behaviour relevant to loading of seismic origin rather than on design recipes.

\section{CANTILEVER SHEAR WALLS}

\section{1 Tall Walls with Rectangular Cross Sections}

A single cantilever shear wall, with a height to depth ratio of over 2 , can be expected to behave as an ordinary reinforced concrete flexural member. The small width of such a section suggests that the problem of instability may arise. Consequently the thickness at the critical region near the base of the wall must be chosen accordingly when considering the floor height as the buckling length.

The strength of such walls can be simply evaluated from conventional axial load-bending moment interaction relationships. The axial compression is often rather small and therefore it does not appreciably reduce the ductility of a properly reinforced rectangular shear wall. Sometimes the code specified load does not require much flexural reinforcement and the designer is tempted to provide steel uniformly distributed over the whole depth of the section. It may be shown from first principles, however, that such arrangement of reinforcement reduces the ductility as the total steel content increases.

* Reader in Civil Engineering, University of Canterbury, Christchurch.
When the flexural steel demand is larger it will be much more efficient to follow the arrangement used in ordinary reinforced concrete beams, i.e. to accommodate much of the flexural steel near the extreme fibres. A minimum of $p_{v}=0.25 \%$ vertical steel should always be provided in the "web" of the shear wall section. However, other considerations, to be discussed later, may require more reinforcement in the "web". The concentration of the flexural steel near the extremities of a rectangular shear wall section will also increase considerably the rotational ductility $(2)$.

The shear strength of tall rectangular shear walls can be assessed the say way as in ordinary beams. It should be remembered, however, that where yielding (near the base of the wall) of the flexural reinforcement can occur the contribution of the cracked concrete towards shear resistance must be neglected and horizontal stirrup reinforcement need be provided for the total shear which is associated with the load causing flexural yielding. Assuming a 45 degree potential diagonal failure crack, this stirrup reinforcement will have to be provided over a height equal to the depth of the shear wall section. This can be more than the floor height. Intermediate vertical bars will not contribute significantly towards shear strength in tall shear walls.

In the upper parts of the cantilever shear wal1 no flexural yielding is expected. Consequently a nominal shear stress of approximately $2 \sqrt{f \&}$ can always be allocated to the concrete. A minimum horizontal wall steel content of $0.25 \%$, when properly anchored, will supply about the same amount of shear strength so that the minimum shear strength available in the elastic portion of a rectangular shear wall is approximately $4 \sqrt{f_{c}}$, in terms of nominal shear stresses.

\subsection{Squat Shear Walls with Rectangular Cross Sections}

In cantilever shear walls whose height, $\mathrm{h}_{\mathrm{w}}$, is comparable with their depth, i.e. $\mathrm{h}_{\mathrm{w}} / 1_{\mathrm{w}} \approx 1$, it is no longer possible to separate the considerations of flexure and shear from each other. The relatively large flexural capacity of these walls can be associated with shear forces which are large enough to destroy the structure in a brittle manner. Hence the consideration of shear strength assumes pre-eminence.

For want of other and better information it was often attempted to predict the likely behaviour of low rise shear walls from tests carried out on deep beams. Geometric similarities suggested such procedures. Most tests on deep beams have a common feature, the load 
is directly applied to the top or bottom faces of simply supported specimens, as shown in Fig. 1a. As the diagonal line of thrust, or internal arch, can dispose of the shear force, vertical stirrups will not be effective. Therefore certain codes suggested that the contribution of web reinforcement should be ignored and the nominal shear stress on low rise shear walls be limited(3). Fig. $1 \mathrm{~b}$ shows that with a different type of 1 oad introduction no effect. ive arch action can develop and hence no substantial shear strength can exist without web reinforcement crossing the potential diagonal failure cracks. Leonhardt and walther demonstrated $(4)$ that when the shear.is introduced as a line load over the depth of a deep beam, stirrup reinforcement is fully effective. One of their specimens together with the applied load pattern is shown in Fig. 2 .

A similar difference in the behaviour of low rise cantilever shear walls exists. Early results were derived from racking tests, with a singla concentrated load being applied against the tension force of a cantilever. In these specimens arch action could develop. In actual shear walls the load is introduced normally as a line load, by means of a floor slab, and a shear disposal similar to that shown in Fig. 2 ensues.

To illustrate the behaviour of squat shear walls, and the effects of both the flexural (vertical) and shear (horizontal) reinforcement on failure mode and ductility, the more important points of a study, carried out at the University of Canterbury (5), are briefly presented in the following.

Square shaped $\left(h_{w} / 1_{w}=1\right) 6 i n$. thick cantilever shear walls were subjected to a load in such a way that the shear force was distributed along their top edge. See Fig. 3. For convenience this is expressed in terms of nominal shear stress, $v$. The properties of three specimens and the results are summarised in Table $I$. The failure mode of each of the test walls is evident from Fig. 3 and Fig. 4.

(i) Wall 203 was deliberately underdesigned for shear. Stirrups were expected to resist only $50 \%$ of the load, which would have been developed if flexure governed the strength. (Row 8 of Table I). Fig. 3 shows the development of diagonal cracks during 12 cycles of the loading. Some of the shear sas still transferred by arch action because $123 \%$ of the theoretical shear capacity and $108 \%$ of the flexual capacity could be developed. Nothing shows better the usefulness of stirrups in such squat shear walls than the fact that at failure one stirrup fractured.

(ii) By providing more vertical reinforcement in all 201 its flexural capacity was approximately twice that of the previous wall. This flexural strength required the development of large shear stresses, i.e. approximately $10 \sqrt{f}$. The design shear strength of the wall was in excess of its flexural capacity, and a flexural failure could be expected. As Fig. 4 a shows a sliding shear failure occurred in the 12 th cycle of loading at $39 \%$ of the theoretical capacity of the specimen. It should be noted that additional stirrup reinforcement cannot prevent this type of failure, which is typical in deep members, where high intensity of cyclic shear occurs. The phenomenon will be discussed in greater detail when the behaviour of deep spandrel beams is reviewed. (iii) Wall 202 was identical to Wall 203 except that shear reinforcement was provided in excess of the flexural capacity. The theoretical flexural strength was associated with moderate nominal shear stresses, i.e. $5.6 \sqrt{f:}$. The specimen exceeded its ultimate design capacity in each of the "plastic" cycles and could not be destroyed as contemplated because the loading frame was unable to match the specimen's ductility. Fig. $4 \mathrm{~b}$ shows Wall 202 at this stage. It is probable that further load reversals would have eventually caused a sliding shear failure.

Fig. 5 gives the 1 oad rotation relationship for all three beams. (Rotation = lateral deflection of wall divided by its height). Cycles 1 to 4 show the elastic response and cycles 7 to 8 indicate the elastic response after one moderate excursion beyond the yield range in each direction was made. The plastic response of each wall can be conveniently expressed by the cumulative ductility, row 10 in Table I. Not only was Wall 201 the least ductile one, but it also showed a distinct loss of the strength. The superior performance of Wall 202 suggests the two important conclusions for design:

(1) If a ductile i.e., flexural failure mechanism is desired in a low rise shear wall than the nominal shear stresses, associated with the flexural capacity of the wall, must

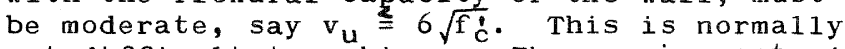
not difficult to achieve. The requirement will limit the flexural steel content in the wall.

(2) Because the flexural failure mechanism is associated with large cracks no reliance should be placed on the concrete in contributing towards shear strength. Consequently, the whole of shear force should be resisted by web reinforcement.

The likely crack patter on a low rise shear wall is sketched in Fig. 8. From considerations of equilibrium of the triangular free body marked 1 , it is evident that horizontal steel is required to resist the shearing stress applied to its top edge. In the free body bound by two diagonal cracks and marked 2, on the other hand, vertical forces of equal intensity need be generated in order to develop the necessary diagonal compression. Hence, thevertical web steel need be the same as the horizontal steel. This is referred to as shear reinforcement even though its principal role is to resist the moment which tends to overturn free body 2 . Appropriate recommendations for this, have now been incorporated in the ACI Code(20).

\section{3 Flanged Cantilever Shear Walls}

There is no reason to expect that flanged shear walls would behave differently from those with rectangular sections. Steel provided in each of the flanges should ensure adequate flexural ductility. Additional safeguards, in forms of lower under-capacity factors, may be appropriate when the whole thickness of a wide flange is in compression(6).

The flanges will considerably boost the moment capacity of tall cantilever shear walls, hence the shear resistance of their webs may become a critical design item. The large demand for web reinforcement can be conveniently met by using steel with higher yield strength (HY60). 
In a well designed shear wall the stirrup reinforcement is not expected to yield at any stage of a seismic disturbance.

\subsection{Flexure - Axial Load Interaction in Shear Wa11s}

Flanged, angle or channel shaped cross sections often appear in shear walls forming the cores of multistorey buildings. Such sections will be subjected to axial forces, including tension, as well as bending moments about either of the principal axes. Because the overall dimensions of cores remain sensibly constant over the rull height of the structure and because more than one load combination may have to be considered it could be advantageous to construct the appropriate interaction curves for moment and axial force. With the aid of a small computer this is a relatively easy task (?).

Fig. " shows the axial force-moment"interaction for two channel shaped shear wall sections. The reinforcement is assumed to be uniformly distributed within the thickness of the wall section. Clearly the section is less sensitive to compression and bending moment causing compression in the "web" of the channel section than to a moment which induces compression at the tip of the "flanges". The position of the neutral axis, at ultimate, $C$, relative to the compression edge is expressed by the C/D ratio, where $D$ is the "flange" width. The balanced failure mechanism, corresponding with an approximate ductility factor of unity, is associated with a C/D ratio of approximately 0.65 in the second example. The interaction curves and the radial lines indicate thus to what extent does the given load combination lead to a ductile failure, such as would be associated for example with $C / D=0.1$. It is apparent from these curves that our experiences with rectangular sections cannot be simply transposed over shear wall sections. The available rotational ductility of the critical shear wall section of given geometry is evidently strongly affected by the senses of the moments and the axial forces i.e. net compression or tension.

\section{5 Horizontal Construction Joints Across Shear walls}

Earthquake damage in shear walls was of ten observed at construction joints, along which sliding movements occurred. These are more common in low shear walls which carry relatively small gravity loads. However, they have also been observed in multi-storey structures (see Fig. 14).

A well prepared construction joint will produce a rough surface and hence it will be able to transfer shearing forces by means of aggregate interlock. This mechanism is also referred to as "shear friction". As soon as a sliding movement commences, a crack, formed along a construction joint, will tend to widen. Any means which will prevent or delay the opening of such a crack will necessarily boost the shear transfer capacity of a construction joint. Any compression force acting across the joint, either applied externally as a load or generated internally by means of vertical reinforcement, can be utilised for this purpose. Its clamping effect is made use of in the tradional sense of the friction concept. When the external com- pression is insufficient or absent the clamping force generated by the vertical reinforcement, which is strained across the crack when it widens, can ensure that substantial shearing forces can be transferred.

A recent research project(8), stimulated by the New Zealand Society of Earthquake Engineering, revealed certain aspects which are briefly summarised. Firstly, however, the basic criteria of the desired behaviour of horizontal construction joints across shear walls, as seen by the author, may be stated.

(a) If possible, a construction joint should not form the weakest 1 ink in the chain of structural resistance. Shear is the governing mode of load transfer. It is therefore necessary that the shear strength of such a joint be equal but preferably larger than the shear (diagonal tension) strength of the shear wall itself.

(b) Under moderate loading shear displacements and crack widening should be small enough not to interfere with functional requirements or require repair.

(c) The required surface preparation should be afforded by simplest possible means.

The current recommended upper limit stress of shear transfer by aggregate interlock is $0.2 \mathrm{f}$ or $800 \mathrm{psi} 20$. This is in excess of the limiting shear (diagonal) stress of $10 \sqrt{f_{c}^{\prime}}$ (psi) accepted for structural members for all concrete with a crushing strength in excess of 2500 psi. Hence for the usual shear wall structure the nominal shear stress capacity of the joint need only be in excess of $10 \sqrt{f \dot{c}}$ (psi).

The clamping force at yield of the vertical steel is $T_{V}=A_{V} f_{y}=p_{v} b d f_{y}$. Hence the frictional shear stress to be relied on becomes $\mathrm{v}_{\mathrm{uj}}=$ $\mu \mathrm{T}_{\mathrm{v}} / \mathrm{bd}=\mu \mathrm{p}_{\mathrm{v}} \mathrm{f}_{\mathrm{y}}$, where the value of the friction coefficient, $\mu$, can be taken conservatively as unity. When well prepared clean, rough surfaces with bond are assured $\mu=1.4$, recommended for monolithically cast concrete, could be used. This was evident from the experiments.

Designers often assumed that the principal mode of shear transfer is dowel action. These and other tests have confirmed, however, that relatively large displacements are required to fully mobilise dowel action. This applies particularly to small size bars. In the useful range of shear displacements, say one third of a small crack width, $(0.01 / 3=0.0033 \mathrm{in}$. the contribution of the vertical reinforcement as dowels is negligible. This is evident from Fig. 8. Only after the breakdown of adhesive bond between the two faces of a construction joint or the yielding of the vertical reinforcement do dowels significantly resist shear forces. This was observed at a shear slip in excess of one tenth of an inch.

Fig. 9 shows the response of construction joints for various surface preparations and a steel content of $0.69 \%$. The lowest curve shows the response of $3 / 8$ in. dowels. It is seen that joints with differently prepared rough surfaces developed an ultimate shear stress much in excess of the suggested value of $1.0 p_{v} f_{y}$. The effect of 1 oss of bond, such as could be caused by a thin layer of laitance, is shown by the third curve from the bottom. The significant feature 
is the larger slip at low loads. Subsequent tests indicated that the recommended shear strength can be sustained several times during alternating cyclic loading. The apex of each curve in Fig. 9 occurred at the onset of yielding in the reinforcement. It was also observed that with a vertical reinforcing content equal or more than $0.69 \%$ sliding shear failure did not occur along the rough bonded construction joint, but rather across the old concrete below the joint. It is known that the quality of this concrete, at the top of a pour, is inferior because of sedimentation, water and air gain. This concrete layer of poor quality will normalIy limit the strength of the region and not the interface along the construction joint. It is suggested that the minimum steel across a horizontal construction joint in a shear wall be determined as follows:

(a) The nominal ultimate shear stress sustained along a joint is.

$$
v_{j u}=\left(N+A_{v} f_{y}\right) / A_{g}
$$

where $\mathrm{N} \quad=$ the axial compression resulting from loading.

$A_{v} f_{y}=$ the clamping force represented by the vertical steel crossing the joint. $A_{g}=h_{w}$ the gross area of the wall

(b) The beneficial effect of the axial compression must not be overestimated. A reduction of at least $20 \%$ should be considered to allow for negative vertical acceleration.

(c) By assuming the effective depth to be eight tenth of the overall depth Eq. 1 can be rewritten thus

$$
\begin{gathered}
v_{j u}=\frac{0.8 N+A_{v} f_{y}}{1.25 h d}=0.8\left(\frac{N}{A_{g}}+p_{v} f_{y}\right) \geqq v_{u} \leqq \\
10 \phi \sqrt{f_{c}}
\end{gathered}
$$

where $v_{u}=$ is the shear (diagonal tension) capacity of the remainder of the wall.

Hence the reinforcing content required is

$$
\mathrm{p}_{\mathrm{v}}>\left(1.25 \mathrm{v}_{\mathrm{u}}-\frac{\mathrm{N}}{\mathrm{A}_{\mathrm{g}}}\right) / \mathrm{f}_{\mathrm{y}} \geqq 0.0025
$$

With a small amount of axial compression and moderate shear stresses, $v_{u}$, the minimum steel content of $0.25 \%$ will suffice to ensure adequate protection of the construction joint. For high shear stresses steel considerably in excess of the nominal quantity will be required. Fig. 10 shows the requirements when $f_{c}=4000$ psi and $f_{y}=40.000$ psi.

(d) It is important that at least this amount of steel be provided over each foot length of wall section. Heavy reinforcement, situated near the edges of the section, will provide the desired clamping force in its immediate vicinity only.

It is emphasized that it does not seem to matter what method of preparation is used for a horizontal construction joint as long as a rough surface with a coarse texture is produced to which the freshly placed concrete can bond. With adequate vertical reinforcement, as out lined above, a shear strength in excess of the diagonal tension strength of the shear wall structure can be assured.

\section{THE INTERACTION OF SHEAR WALLS WITH EACH OTHER AND WITH FRAMES}

Only seldom will a single cantilever wall be called upon to resist the whole of the lateral load acting upon a multistorey struct ure. It is more likely that a number of such walls will share in the total load resistance. In the majority of multistorey buildings shear walls will occur around the service core and rigid jointed frames are likely to carry the gravity load over the remainder of the floor. It is beyond the scope of this review to discuss the techniques of analysis which are available $(14,15,24)$ to deal with the problem of interaction between different lateral load resisting subassemblies. However, on one aspect, which most designers are aware of, a warning may be warranted.

The response of rigid jointed frames and cantilever shear walls to lateral loads can be so markedly different, particularly in the upper storeys, that undesirable interaction may ensue. The two types of structures may work against each other, and an unusually large ductility demand may possibly result in the process of developing the ultimate strength of the whole structure $(9)$

\section{SHEAR WALLS WITH OPENINGS}

Openings for windows and doors in shear walls cannot be avoided. However, the designer should be aware at the early stages of the planning that the arrangement of these must ensure a rational structure. The behaviour of these can be assessed by bare inspection. Irrational shear walls on the other hand defy an attack by the conventional techniques of structural analysis. Moreover such structures often invite disaster by concentrating energy absorbtion at a few localities which are unable to supply the unusually high demand for ductility. A few examples of such structures and their response to earthquakes were given elsewhere $(6,9)$.

\section{COUPLED SHEAR WALLS}

The common shear wall will contain one or more columns or rows of regular openings. These structures lend themselves to rational analysis. The prototype structure is the shear core of a multistorey building in which two or more flanged cantilever walls are interconnected by short and relatively deep "coupling" beams. (See Fig. 11). The analysis of these requires also the consideration of axial deformations in the walls and shear distortions of the coupling beams. For this reason conventional hand computations are inadequate. However, by suitable modelling of the structure the analysis can be considerably simplified for hand or computer processing. The essential ingredient of this technique is the replacement of the discrete beams by a continuous set of elastic "laminae", hence the reference "laminar analysis" or "continuum approach". The technique has been well covered in the 1 iterature $(10,11$, $12,13)$ and details of it are beyond the scope of this review. The mathematical model and the 
equivalent properties are shown in Fig. 11.

\section{1 The Elastic Response of Coupled Shear Walls}

In similarity to a castellated beam the coupled shear wall structure resists the external overturning moment, $\mathrm{M}_{\mathrm{O}}$, (with reference to Fig. 11) by

(a) internal moments $M_{1}$ and $M_{2}$, generated in Wall 1 and Wall 2 respectively and by

(b) axial forces, $T$, generated in each wall and operating on a lever arm, 1. The axial force, which at any 1 evel is the sum of all the shearing forces across the coupling beams or laminae situated above that level, generates tension in one wall and compression in the other. The aim of a laminar analysis is to determine the relative magnitudes of these components which are related to each other by the simple equilibrium statement;

$$
M_{0}=M_{1}+M_{2}+1 T
$$

The interplay between the modes of internal moment resistance, Eq. 3, depends on the strength and stiffness of the coupling system. Clearly it is more efficient to resist the external moment predominantly by internal forces, $T$, which operate with a large lever arm, 1, than by component internal moments, $M_{1}$ and $M_{2}$. The relative proportions of the contribution of the internal couple, $1 \mathrm{~T}$, in resisting the external moments, $M_{O}$, at various levels of an elastic 20 storey shear core are shown in Fig. 12. It is seen that the coupling is efficient for the top half of the structure for a 11 but the shallowest beams. At the base little difference in behaviour is indicated for $24 \mathrm{in.}$ deep or infinitely stiff beams. The latter represent the case when no distortions occur in the process of shear transfer from one wall to another, i.e., a continuous linear strain distribution occurs across the entire shear wall structure. The low efficiency of 6in. deep coupling beams shows the approach to the other limiting situation, when $1 \mathrm{~T}=0$, i.e. when the entire external moment is resisted by flexure in the component walls, $M_{1}$ and $M_{2}$.

The role of cracking in the elastic behaviour of shear walls has been examined Because of the very large differences between the stiffnesses of the components and the drastic loss of stiffness in the coupling system after diagonal cracking, deflection and wall moment $\left(M_{1}\right.$ or $\left.M_{2}\right)$ increases of $75 \%$ to $100 \%$ have been obtained in case studies, when allowance was made for cracking.

\subsection{The Elasto-P1astic Response of Coupled Shear Wa11s}

The ultimate strength of coupled shear walls, subjected to seismic type of lateral loading, is attained when a statically admissible mechanism is formed in which each of the required plastic hinges possesses adequate rotational capacity. Two hinges in each coupling beam are required to terminate its ability to accept further shear. In addition, one plastic hinge need be developed in each of the cantilever walls, normally at their base, to complete the collapse mechanism. The sequence of hinge formation will depend upon the relative strength and stiffness of the components.
The behaviour of some coupled shear walls, which were exposed to severe earthquakes, indicated that all or most coupling beams failed before the ultimate strength of the coupled walls was attained. A classic example of this is shown in Fig. 13 and Fig. 14. This indicates that ductility demands in excess of these beams' capacity may have existed. In the following, an example will be used to show how and where these excessive ductilities may develop.

\subsection{A Deterministic Design Approach}

One may adopt a deterministic approach and dictate a desirable sequence of plastic hinge formations for a given lateral static load whi ch is assumed to increase monotonically to its ultimate value. The plastic hinges in the wal1s, which are also major gravity load carrying units, should be the last ones to form. Each of the two walls is subjected to axial forces, generated by the lateral load, which could restrict their ductilities. Therefore, the attempt of delaying hinge formation in the walls should also result in benefits in terms of reduced ductility demand.

The major steps of a design approach based on these principles are outlined very briefly here with the aid of an example structure. The basic dimensions of the core of a 20 storey building are tho se shown in Fig. 12 . The lateral code load consists of a triangular block, $W=600 K$, and a point load at roof level $\lambda W=80 \mathrm{~K}$, as sketched in Fig. 12. The elasto-plastic analysis is based on the model of laminar coupling 18$)$. The beams and the walls are assumed to conform with idealised elasto-plastic bilinear behaviour during the process of plastic hinge formation.

(i) The stiffness properties, based on the gross area of the components need be established first. The loss of stiffness caused by cracking can be estimated to ensure a more realistic evaluation of the elastic response. Typical reduction multipliers, applicable to the properties of the components in the uncracked state, are as follows:

Second moment of area of tension wall 0.50 Area of tension wall

Flexural stiffness of coupling beams, which also includes an allowance for shear distortion

Properties of compression wall

With these properties the internal actions can be determined. The typical distribution of the laminar shear force, q, laminar rotation, $\theta$, in terms of the laminar yield rotation, $\theta_{y}$, and the deflection at roof level, y, are shown for the example structure in Fig. 15a. This is STAGE 1. All results are marked in Fig. 15 accordingly with the circled number 1

(ii) After an examination of the laminar shear intensity it may be decided how much overload would be acceptable before the yield (ultimate) strength of the critically situated lamina or coupling beam is attained. In the example $30 \%$ was chosen. Therefore, at up to 1.3 times the code load all components are assumed to remain in the elastic range. This is STAGE 2 and it is marked accordingly in Fig. 15a. As this is the elastic 1imit of the structure, i.e. the point of first yield, 
the overall ductility can be expressed in terms of the deflection at roof level at this load, ye.

The required capacity of the coupling beam at $x \approx 0.7 H$ is now established and consequently the appropriate reinforcement can be determined. Details of this are discussed in a subsequent section. According to a decision, made in this example, all beams throughout the height will receive the same reinforcement.

(iii) An additional load, $\Delta w(1+\lambda)$, can now be imposed so that the ultimate-strength of at least the upper $90 \%$ of the laminae, $q_{u}$, is developed. To ensure this the relative stiffnesses of the components need be taken into account (18). At this STAGE 3 of the loading the walls are still elastic. However, the coupling beams were forced through various amounts of plastic distortions. This is measured by the imposed ductility factor as shown by the appropriate curve in Fig. $15 \mathrm{a}$. It shows that a beam situated at $x=0.6 \mathrm{H}$ will have to supply a ductility factor a little over 3, whereas the topmost 1 anina just yields.

The maximum axial load generated in the walls by this external load of $(1.3+\Delta)(1+\lambda) W$ is derived from the summation of all laminar shears. This is $T_{u} \approx 0.95 \mathrm{Hq}_{u}$. In absence of strain hardening this value cannot be exceeded during future loading. In the example structure $T_{U}=2000 \mathrm{~K}$.

The gravity load on the structure is known and thus the ultimate intensity of axial force in both wals can now be determined. Usually $T_{U}$ is the most significant component of the axial force. In evaluating the gravity load effect due allowance need be made for positive and negative vertical acceleration so as to obtain the most adverse combination of axial loading separately for each wall.

(iv) For any subsequent and additional loading the two walls can be assumed to act as elastic interconnected cantilevers till the flexural capacity of one is reached. In the case of the example it is assumed that an incremental load of $\Delta^{\circ}(1+\lambda) w$, equal to $5 \%$ of the original load on the coupled shear wall structure, can be applied when the flexural capacity of wall $1, M_{1, u}$ is attained in the presence of an axial force, determined in the previous stage. All information related to this STAGE 4 of the idealised behaviour is accordingly labelled in Fig. $15 \mathrm{a}$.

(v) The rinal load increment to be applied against the nearly fully plastic structure, $\Delta(1+\lambda) W$, is assumed to develop the ultimate flexural capacity of wall $2, M_{2}, u$, simultaneously with the maximum compression exerted on that wall. The value of $\Delta$ has again been taken 0.05 in the example. In this Stage 5 the collapse mechanism is assumed to have been completed. Any additonal tilting of the structure will accordingly cause plastic rotations in al 1 previously formed plastic hinges.

All information for the design of the shear wall sections is now available, i.e. $P_{1}, u, M_{1}, u, P_{2}, u, M_{2}, u$ With the use of appropriate interaction diagrams or from first principles the required steel contents, $p_{1}$ and $\mathrm{p}_{2}$, are determined. Clearly, in a symmetrical structure, such as shown in the example, there cannot be different reinforcement requirements for each of the walls. Whichever is larger of $p_{1}$ or $p_{2}$ is 1 ikely to be adopted for both walls. The capacity of the structure is thus increased and the small change in behaviour can be retraced if desired.

The total lateral load resistance is now known. $W_{u}=\left(1.3+\Delta+\Delta^{\prime}+\Delta "\right)(1+\lambda) W$ in the example. Hence the available load factor at the end of the first trial is found, $W_{u} / W$. In case of the example structure this is $1130 / 600=$ 1.88. As no allowance has been made for undercapacity factors, $\phi$, so far this load factor appears to be adequate. Changes of dimensions may be made now if desired and with these the previous design steps could be repeat ed if necessary.

(vi) In order to evaluate the ductility demand for th e coupling beams, which is one of the principal aims of this process, the required overall ductility must be imposed on the structure. In the example structure an inelastic roof displacement of 3 times that at the elastic limit, stage 2, has been imposed in accordance with a current1y accepted value of 4 for a desirable overall ductility factor. This is STAGE 6 of the behaviour. The loaddeflection curve in Fig. $15 \mathrm{a}$ indicates that the ductility factors required for the wall hinges are approximately 2.5. The corresponding value for the critically situated coupling beam is however 11.8. This is of the order of the maximum ductilities attained in conventionally reinforced test beams with a span to depth ratio of two (19). The ductility demand of deeper and stiffer beams of coupled shear walls increases. However, their plastic rotational capacity decreases because of increased detrimental shear effects $(16)$.

In the example chosen, all coupling beams were provided with the same strength capacity. However, it is feasible that the strength of each beam is made proportional (or approximately so) to the elastic strength demand. Such an example was also considered and the results of the previously outlined stepwise design are given in Fig. 15b. In this structure all laminae are assumed to yield at the same time, stage 2 and stage 3. It is seen that smaller ductility demands ensued for the more heavily reinforced beams in the lower portion of the structure. For the lighter beams, situated in the top third of the height, however, considerably larger ductility demands exist. For most real coupled shear wall structures intermediate ductility demands for the coupling system can be expected.

\subsection{The Strength of the Coupled Walls}

The bending moment pattern on one of the coupled shear walls will normally be similar to that of simple cantilever walls. However, because of the coupling system considerable axial forces may also be present. These may produce net tension in one of the walls. The design consideration applicable to any section of a coupled shear walls are therefore no different from those outlined in 2.3, where the interaction of flexure and axial load was considered. See also Fig. 7 .

\subsection{The Strength and Ductility of Coupling Beams} observations of earthquake damage have 
repeatedly shown that coupling or spandrel beams, containing insufficient web reinforcement, failed by diagonal tension. (See Fig. 14.) Clearly, such failures, usually brittle, which follow a high rate of strength degradation under cyclic loading, must be supressed if a satisfactory seismic resistance is to be provided. Irrespective of the design loads the shear strength of a coupling beam must be equal or larger than its provided flexural capacity. This requirement may impose an upper limit on the flexural steel contant in such beams, particularly when they are deep relative to their span.

The currently accepted upper limit for the nominal shear stress across a beam $(20)$ is

$$
v=10 \phi_{\mathrm{V}} \sqrt{f_{\mathrm{c}}}
$$

and thus the maximum shear force to which a coupling beam is subjected should be

$$
v_{u} \leqq 10 \phi_{v} \mathrm{bd} \sqrt{f_{c}}
$$

With reference to Fig. 11 and Fig. 16 the shearing force corresponding with the flexural capacity of a typical beam is, with good approximation,

$$
v_{u}=\frac{2 M}{s}=\frac{2}{s \phi_{m}}\left(d-d^{\prime}\right) A_{s} f_{y}
$$

where $\phi_{v}=$ under capacity factor in shear $=.85$ $\phi_{\mathrm{m}}=$ under capacity factor in flexure

By equating the shear capacities, i.e., Eq. (4) and Eq. (5), it is found that

$$
\frac{A_{s}}{b d} \leqq p_{\max }=\frac{4.7 s \sqrt{f_{c}}}{\left(d-d^{\prime}\right) \hat{f}_{y}}
$$

It may be noted that all reinforcement in the tension zone of the beam section is included in the flexural strength evaluation (see Fig. 16).

One might be led to believe that such beams, because of the equal amount of top and bottom reinforcement, would possess very large ductility. Considering pure flexure Blume et. al. have shown this convincingly for ordinary reinforced concrete beam sections(21).

For beams with a span to depth ratio of less than 2 the shearing forces and consequent diagonal cracking causes tension to develop in both the top and the bottom reinforcement over the entire span. The smaller this aspect ratio the larger is the tensile stress in the reinforcement at a location where, according to conventional flexural theory, compression stresses should be generated. Theoretical considerations, based on the behaviour of diagonally cracked deep reinforced concrete beams, have shown this and experiments have verified the phenomenon $(9,22)$. It must be concluded that the compression reinforcement in deep coupling beams does not function as such. The concrete is not relieved in compression by the reinforcement and relief with respect to ductility cannot be expected either.

Irrespective of the amount of web reinforcement used, the bulk of the shearing force must be transferred across the concrete com- pression zone of the beams into the shear wal1s. However, the concrete in these areas could have been cracked, opened and closed several times during preceding load cycles and therefore its load carrying capacity in shear would be drastically reduced. Indeed deep beams, fully reinforced against a possible diagonal tension failure, have been observed to fail in direct sliding shear along the critical support section. Fig. 17, showing a beam with an aspect ratio of 1.29 , illustrates this type of failure.

Both, the ineffectiveness of the compression reinforcement and the danger of sliding shear failure are 1 ikely to restrict the plastic rotational capacity of coupling beams. Indeed it appears to be advisable to limit the shear capacity of conventionally reinforced coupling beams by restricting the flexural steel content to

$$
p_{\max }=\frac{3 s \sqrt{f_{c}}}{(d-d \cdot)_{y}}
$$

These findings led to a study of alternative solutions for more effective coupling beams. In a number of tests at the University of Canterbury diagonally reinforced beams were studied. In these the horizontal flexural reinforcement and the stirrup steel required for shear resistance were omitted and only nominal horizontal and vertical bars were used for "basketing" purposes. A prototype beam, recommended for use in shear wall structures, is shown in Fig. 18. After first yielding in each direction the diagonal tension and compression forces are resisted entirely by the diagonal reinforcement, as the concrete will contain numerous large diagonal cracks. It is imperative that the buckling of the compression diagonals is prevented. This will require closely spaced ties or spiral binding near the four corners of such a beam, as shown in Fig. 20, so as to form a reinforcing cage with some flexural rigidity with respect to lateral displacements, i.e. buckling. The spacing of these ties near the centre of the beam must be large enough to enable concrete to be placed into and distributed within the beam.

Experiments verified the superior performance of diagonally reinforced beams. They exhibited ductilities we 11 in excess of those obtained for conventional coupling beams $(22,23)$. Fig. 19 compares the results of the Canterbury tests (23). Both types of beams were subjected to approximately the same pattern of cyclic loading, hence the displacement ductilities, accumulated during progressive loading, can be considered as suitable means for the purpose of such comparison. The relatively small loss of strength during the elasto-plastic cyclic loading of diagonally reinforced coupling beams is most evident.

\section{A. CONCLUSION}

To ensure a satisfactory performance, when coupled shear wall structures are exposed to severe seismic shocks, it is necessary to be able to assess, at least approximately, their behaviour in both the elastic and plastic range of loading. A desirable behaviour can only be expected if the structure is made capable to follow a predetermined sequence of plastification. Such a desire dictates that the wall 
components be the last ones to suffer during the process of imposing incremental ultimate conditions.

The strength considerations of conventionally reinforced coupling beams require not only full protection against diagonal tension failure during cyclic loading, but also moderate flexural steel content in both faces to give maximum ductility and to avoid early failure by sliding shear. When diagonal principal reinforcement is used in coupling beams and adequate ties are provided to enable the compression struts to sustain a yield load without buckling, satis. factory performance can be expected. These beams have been found to meet much more successfully the ductility demands indicated by

theoretical studies.

The assumptions, upon which the elastoplastic response of shear walls was assessed, can only be satisfied if secondary failures do not occur. As in any other reinforced concrete structure, only the most meticulous detailing of the reinforcement can assure this.

\section{REFERENCES}

1. Symposium on Ta11 Buildings with Particular Reference to Shear wall structures. University of Southampton. Pergamon Press, 1967.

2. Research and Development Laboratories, Cement and Concrete Research Institute, Portland Cement Association, Skokie, Illinois. April, 1972. Private communication.

3. Paulay, T. "The shear strength of Shear Walls", Bulletin of the New Zealand Society of Earthquake Engineering, Vol. 3, No. 4, Dec., 1970, pp. 148-162.

4. Leonhardt, F. and Walther, R., "Wandartige Traegar", Deutscher Ausschuss fuer Stahlbeton, No. 178, 1968.

5. Beekhuis, J., An Experimental study of Squat Shear Walls", M.E. Report, Department of Civil Engineering, University of Canterbury, Christchurch, New Zealand, 1971, p. 132.

6. Park, R. and Paulay, T., "U1timate Strength Design of Reinforced Concrete Structures", Vol. 1. Second Ed., University of Canterbury, 1969, p. 277.

7. Paulay, T.s "An Approach to the Design of Coupled Shear Walls", Proceedings of the Third Australasian Conference on the Mechanics of Structures and Materials, University of Auckl and, Aug., 1971.

8. Phillips, M. H., Morizontal Construction Joints in Cast-in-situ Concrete", M.E. Report, Department of Civil Engineering, University of Canterbury, Christchurch, New Zealand, 1972, $p=95$.

9. Paulay, T., "Reinforced Concrete Shear Wa11s", New Zealand Engineering, Vol. 24 , No. 10, Oct., 1969, pp. 315-321.

10. Beck, H., "Contribution to the Analysis of Coupled Shear Walls", Proceedings ACI Journal, Vol. 59, August, 1962, pp. 10551070 .

11. Rosman, R., "Approximate Analysis of Shear Walls Subject to Lateral Loads", Proceedings ACI Journal, Vol. 61, June, 1964, pp. 717733.

12. Burns, R. J., "An Approximate Method of Analysing Coupled Shear Walls Subject to
Triangular Loading", Proceedings Third World Conference on Earthquake Engineering, 1965, New Zealand, Vol. III, pp. IV-123-140.

13. Paulay, T., "A Discussion of the Analysis of Coupled Shear Walls", by Coull, A., and Choudbury, J. R., Proceedings ACI Journal, Vol. 65, March, 1968, pp. 237-239.

14. Khan, F. R. and Sbarounis, J. A., "Interaction of Shear Walls and Frames", Journal of the Structural Division, American Society of Civil Engineers, Vol. 90, No. ST3, June 1964, pp. 285-335.

15. "Design of Combined Frames and Shear Walls", Advanced Engineering Bulletin No. 14. Portland Cement Association, Skokie, Illinois, 1965 , p. 36 .

16. Paulay, T., "Coupling Beams of Reinforced Concrete Shear walls", Journal of the Structural Division, American Society of Civil Engineers, Vol. 97, No. ST3, March 1971 , pp. 843-862.

17. Berg, V. B. and stratta, J. L., "Anchorage and the Alaska Earthquake of March 27, 1964", American Iron and Steel Institute, New York, 1964, p. 63.

18. Paulay, T., "An Elasto-plastic Analysis of Coupled Shear Walls", Proceedings ACI Journal, Vol. 67, No. 11, Nov., 1970, pp. 915-922.

19. Beekhuis, W. J., "An Experimental Study of Squat Shear Wal Is", M.E. Report, Department of Civil Engineering, University of Canterbury, Christchurch, New Zealand, 1971 , p. 132 .

20. "Building Code Requirements for Reinforced Concrete". (ACI 318-71), ACI Standard, 1971, p. 78 .

21. Blume, J. A., Newmark, N. M. and Corning, L. H., "Design of Multistorey Reinforced Concrete Buildings for Earthquake Motions. Portland Cement Association, Chicago, 1961, p. 318 .

22. Paulay, T., "Simulated Seismic Loading of Spandrel Beams", Journal of the Structural Division, American Society of Civil Engineers, Vo1. 97, No. ST9, Sept., 1971, pp. 2407-2419.

23. Binney, J. R., "Diagonally Reinforced Coupling Beams", M.E. Report, Department of Civil Engineering, University of Canterbury, Christchurch, New Zealand, 1972, p. 131.

24. ACI Committee 442, "Response of Buildings to Lateral Forces", Proceedings ACI Journal, Vol. 68, No. 2, Feb., 1971, pp. 81-106. 
TABLE I

PROPERTIES OF SQUARE SHAPED CANTILEVER SHEAR WALLS

TESTED AT THE UNIVERSITY OF CANTERBURY

\begin{tabular}{|c|c|c|c|c|c|}
\hline- & Specimen number & - & 203 & 201 & 202 \\
\hline 1 & Total vertical steel & $\%$ & 1.43 & 3.21 & 1.43 \\
\hline 2 & Vertical steel in web & $\phi$ & 0.20 & 0.31 & 0.20 \\
\hline 3 & $\begin{array}{l}\text { Theoretical flexural } \\
\text { capacity, } \mathrm{P}_{\mathrm{u}^{*}}\end{array}$ & Kips & 38.0 & $76 \cdot 5$ & 38.0 \\
\hline 4 & $\begin{array}{c}\text { Theoretical shear } \\
\text { capacity, } \mathrm{V}_{\mathrm{u}^{*}}\end{array}$ & Kips & 33.4 & $79 \cdot 5$ & 59.6 \\
\hline 5 & $\begin{array}{l}\text { Theoretical shear } \\
\text { capacity of stirrups, } \mathrm{V}_{\mathrm{s}}{ }^{*}\end{array}$ & Kips & 19.0 & 71.3 & 46.0 \\
\hline 6 & Maximum load attained, $\mathrm{P}_{\mathrm{u}}$ & Kips & 41.0 & 80.7 & $45 \cdot 5$ \\
\hline 7 & $\frac{\text { Maximum 1oad }}{\text { Design capacity }}=\frac{P_{u}}{V_{u}^{* o r} P_{u}^{*}}$ & - & 1.23 & 1.05 & 1.20 \\
\hline 8 & $\left(v_{s} * / P_{u}^{*}\right)$ & $\phi$ & 50 & 93 & 121 \\
\hline 9 & $v_{\max } / \sqrt{f_{c}^{\prime}}$ & - & $5 \cdot 5$ & 10.8 & 6.7 \\
\hline 10 & Cumulative ductility factor & - & 46 & 30 & 56 \\
\hline 11 & Failure mode & - & $\begin{array}{l}\text { Diagona } 1 \\
\text { tension }\end{array}$ & $\begin{array}{l}\text { Sliding } \\
\text { shear }\end{array}$ & Flexure \\
\hline
\end{tabular}

(4) The contribution of the concrete towards shear strength was allowed for in accordance with the current ACI Code 20 .

(8) The ratio of the load provided for with stirrups and the theoretical flexural capacity.

(9) To allow comparison with the maximum nominal shears stress of $10 \sqrt{f_{i}}$, allowed by the ACI Code 20 .

(10) The sum of the ductility factors associated with each cycle of loading accumulated until failure. 
(a)

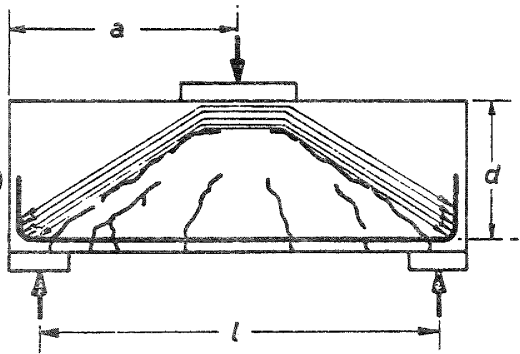

(b)

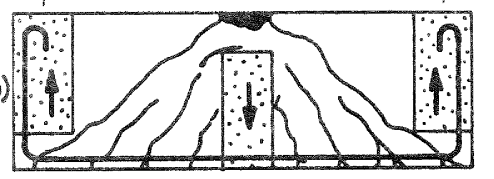

Fig. 1 Arch action as affected by the introduction of load into a beam.
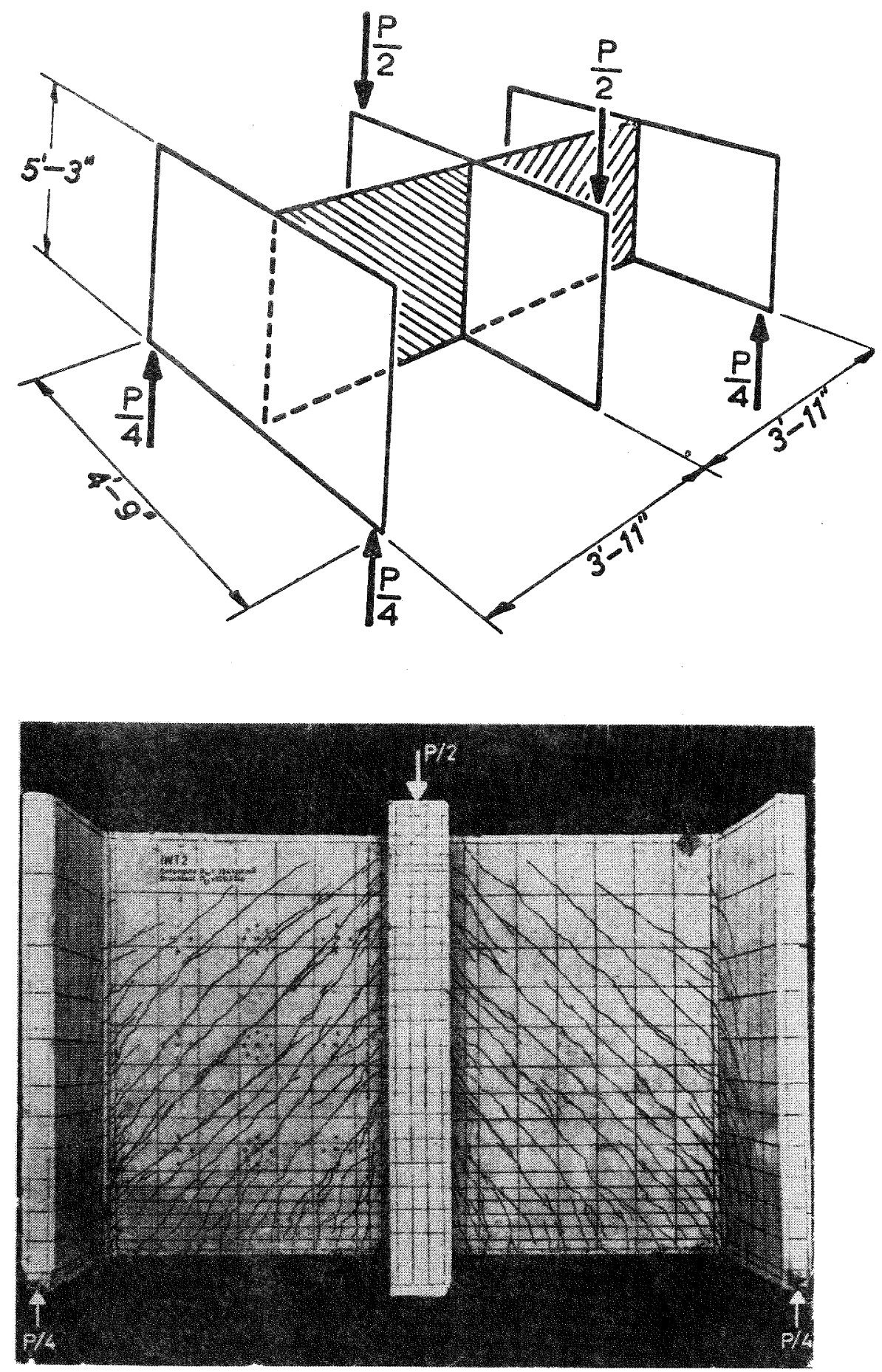

Fig. 2 The loading and crack pattern of a deep beam ${ }^{4}$. 

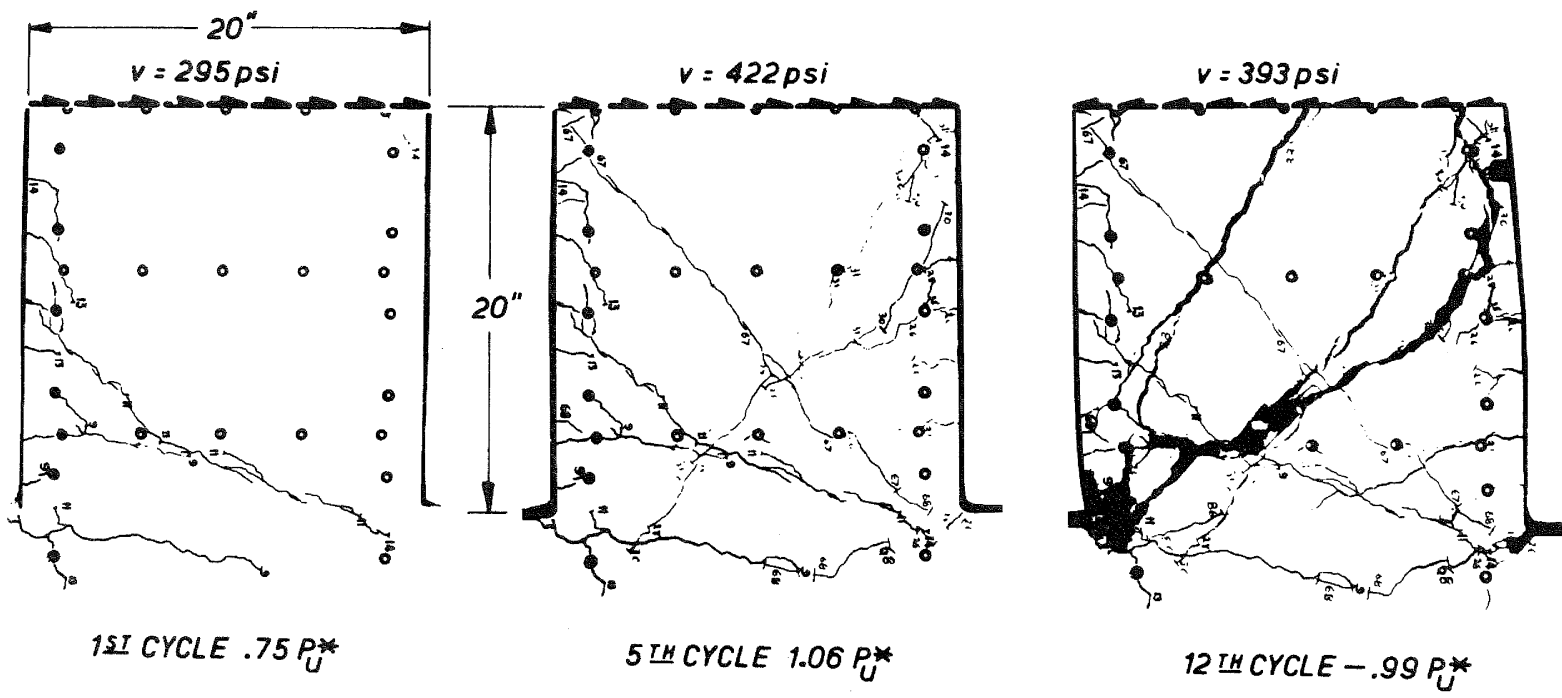

Fig. 3 Diagonal tension failure in a square shear wall model (Wall 203).

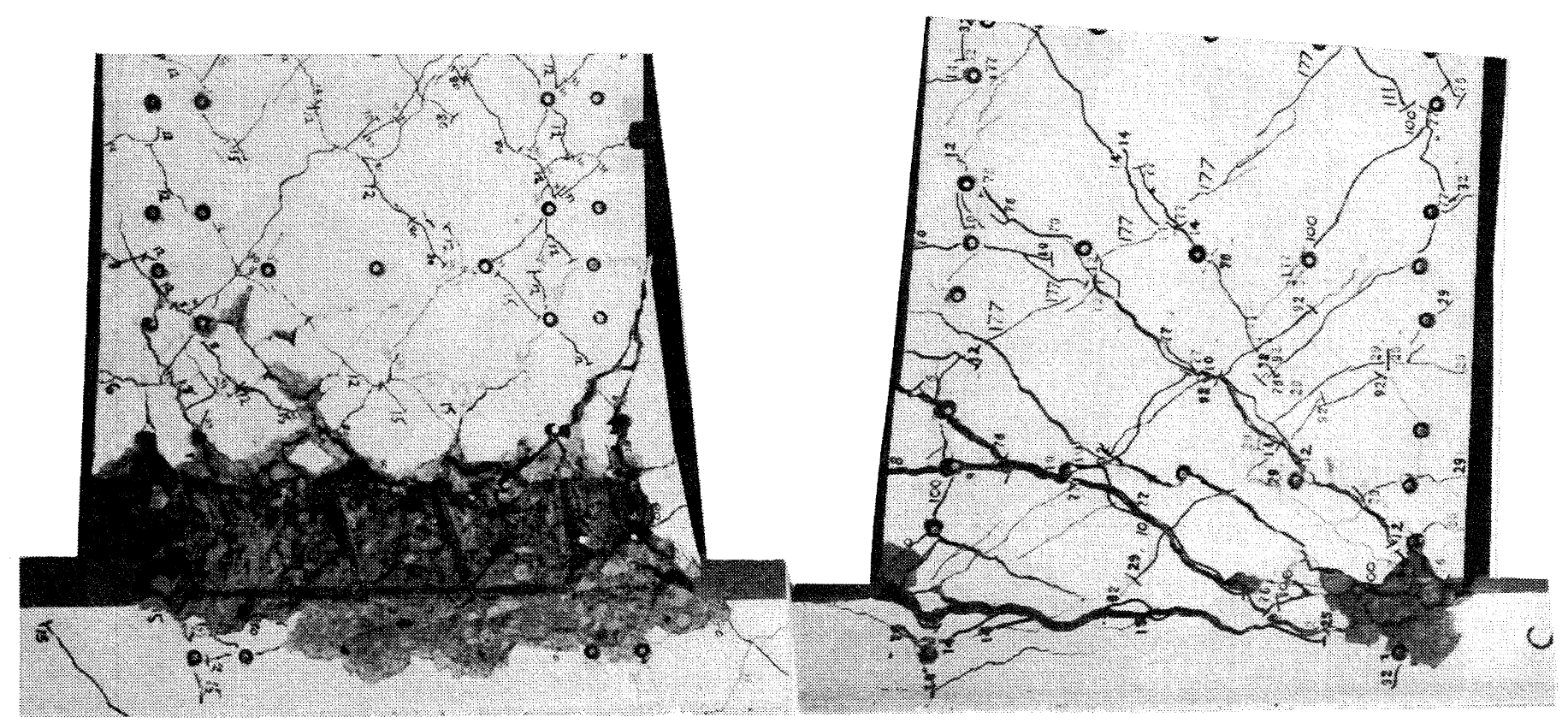

Fig. 4 The failure of squat shear wall models due to sliding shear and flexure. 

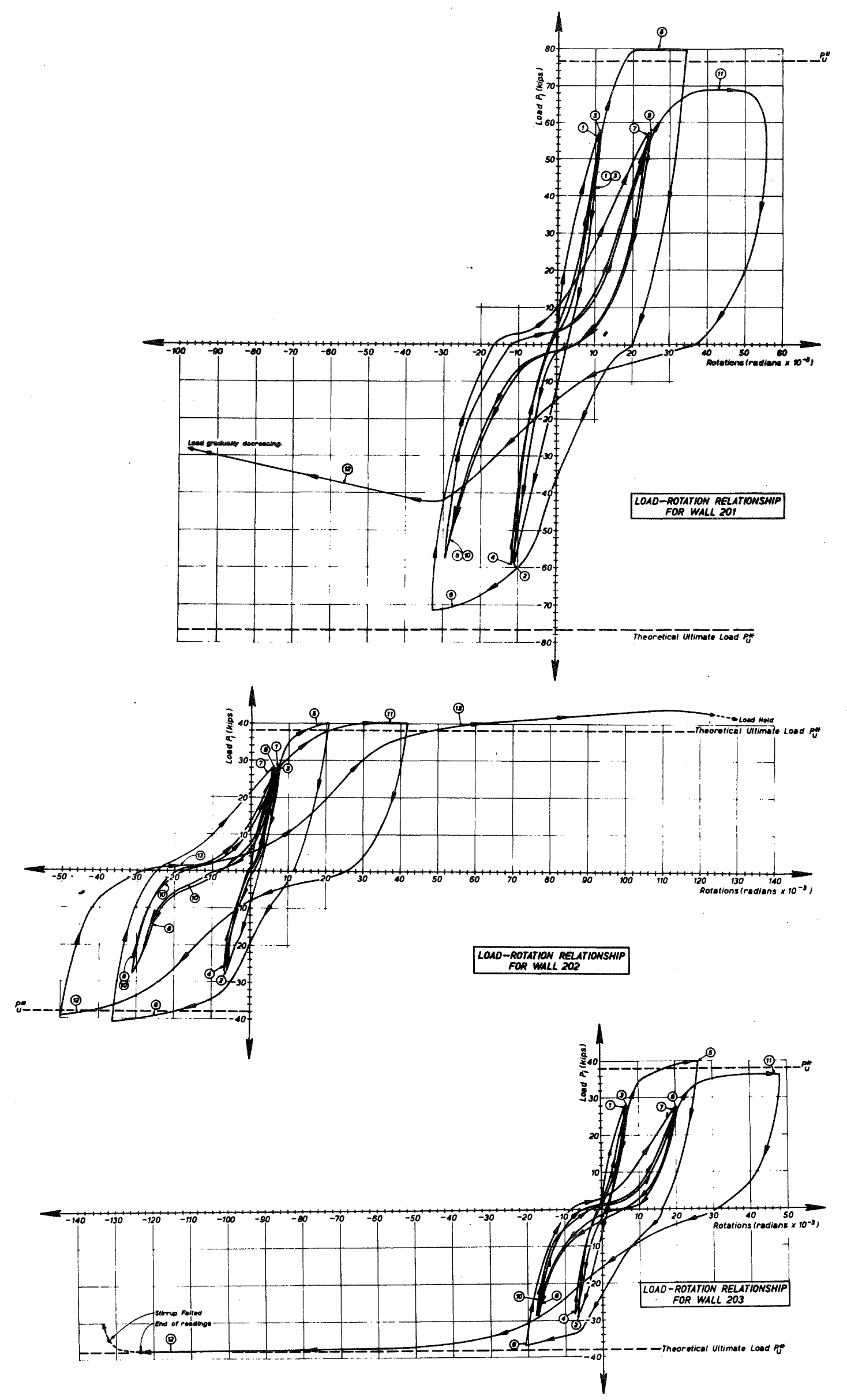

Fig. 5 Load-rotation relationships of squat shear walls subjected to cyclic loading. 

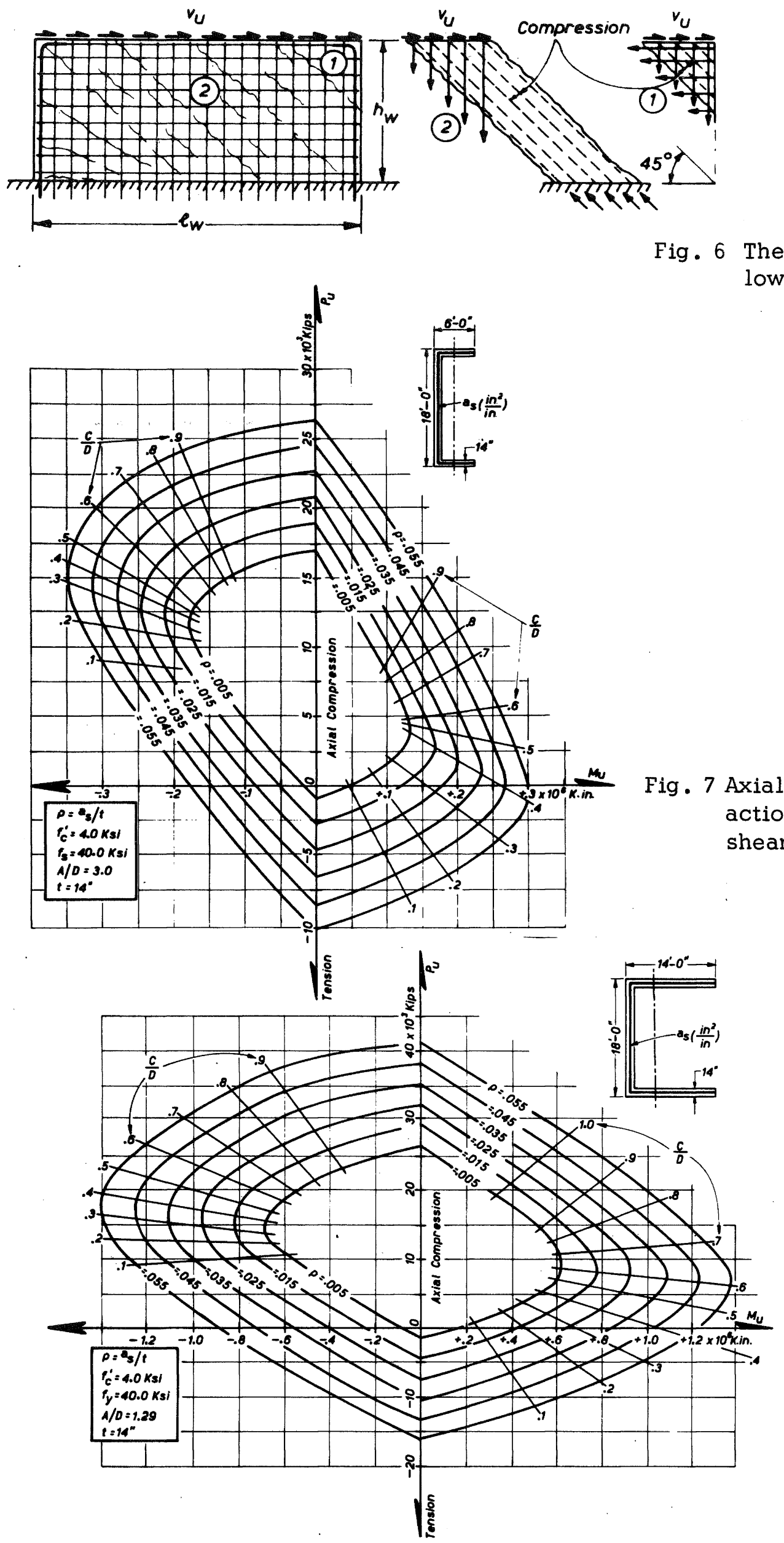

he shear resistance in ow rise shear walls. action for channel shaped shear wall sections. 


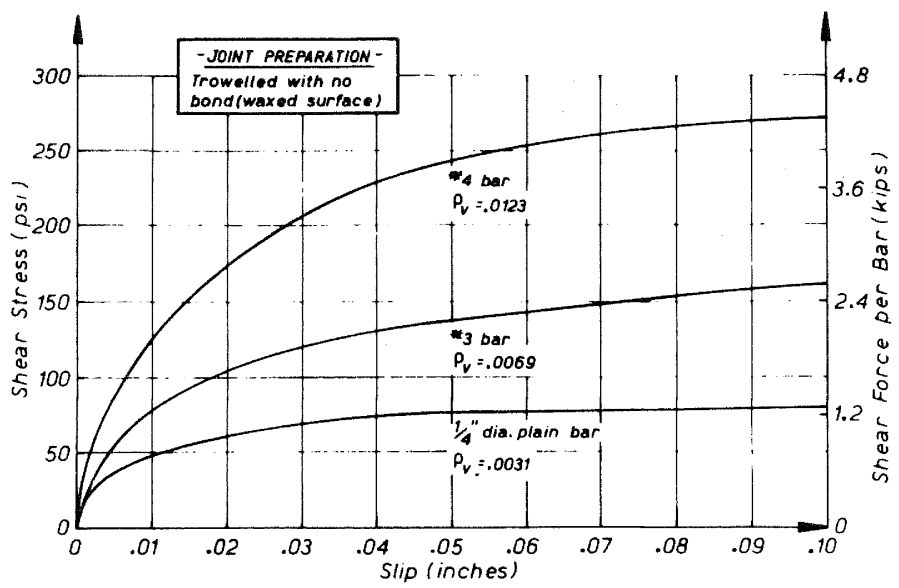

Fig. 8 Load-slip relationships for the dowel action of small diameter bars ${ }^{8}$.

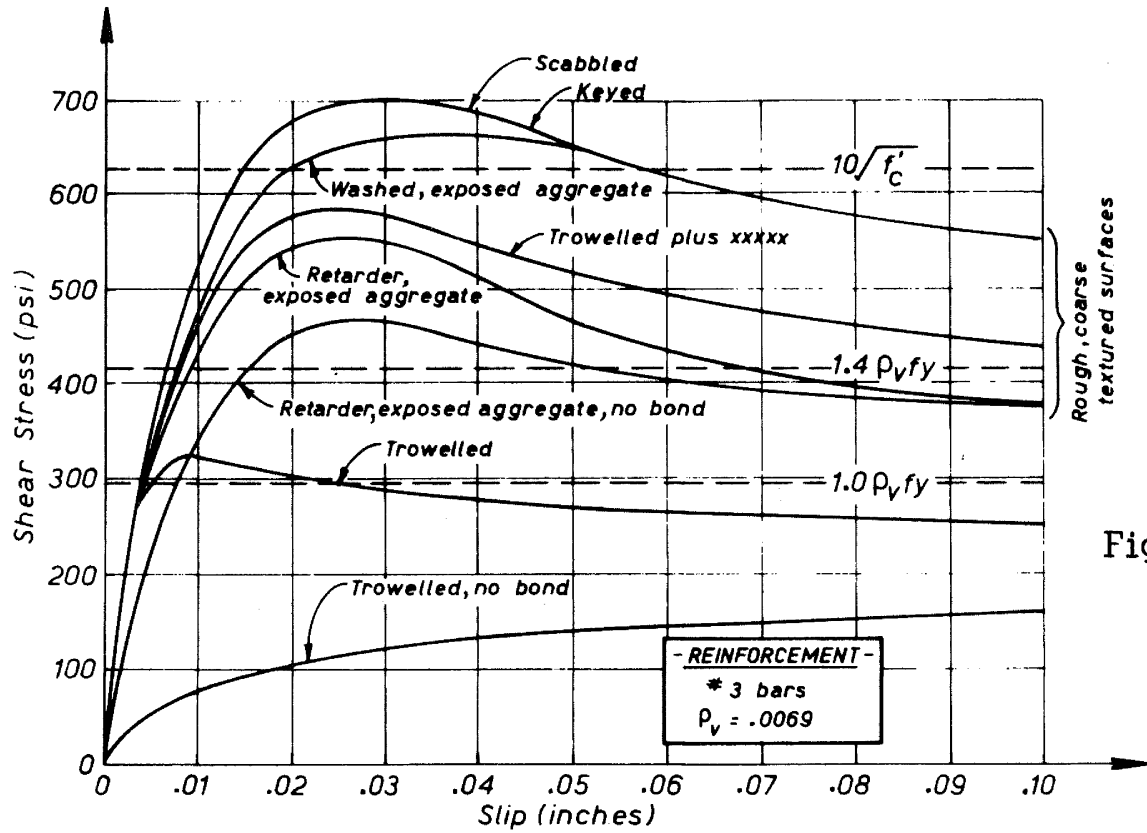

Fig. 9 Nominal shear stress-slip relationships for various surface preparations of construction joints ${ }^{8}$.

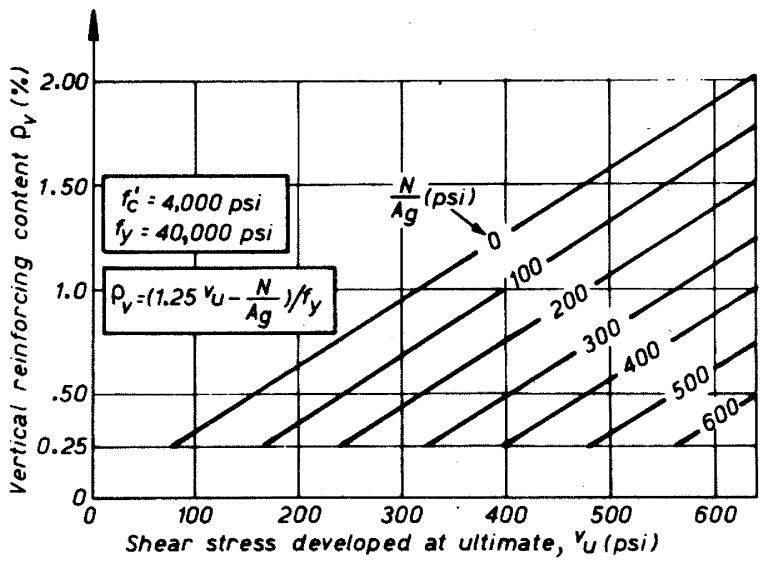

Fig. 10 Steel requirments across a horizontal construction joint . 


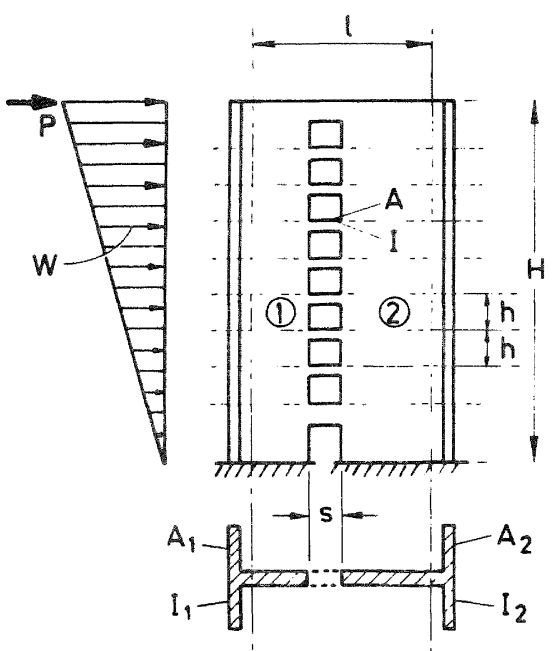

(a)
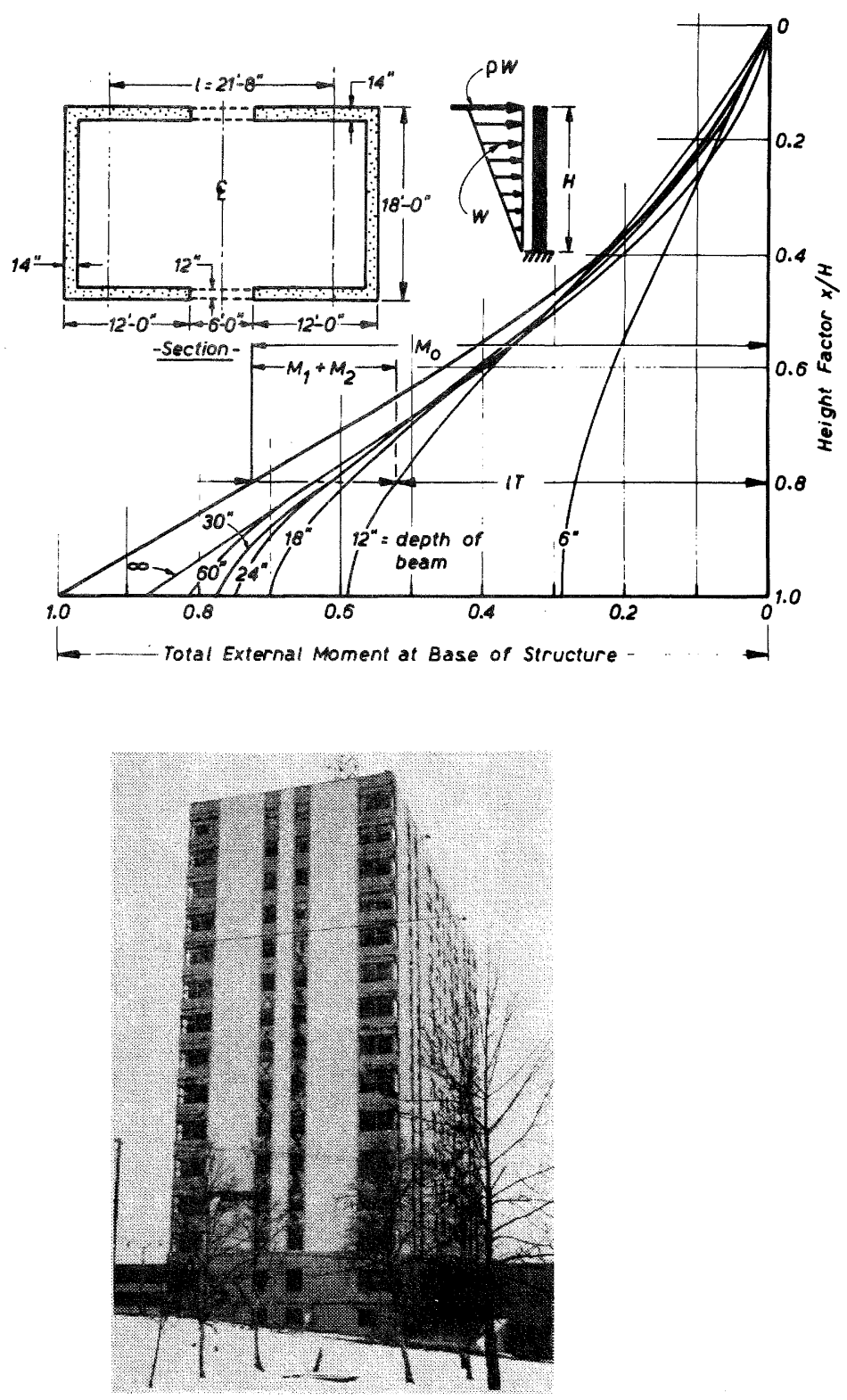

Fig.13 A 14 storey building in Anchorage during the March 27,1964 Alaska earthquake 17 .
Fig.11 A prototype coupled shear wall structure and its mathematical model.
Fig.12 The mode of internal moment resistance in a coupled shear wall structure.

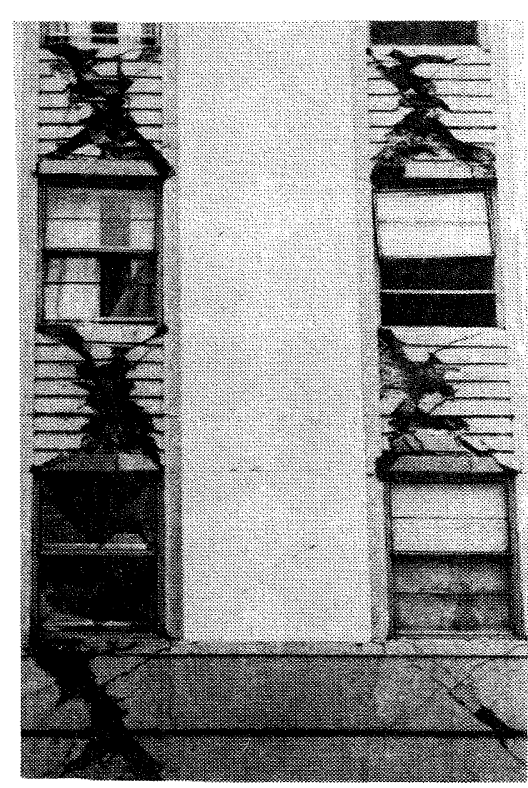

Fig.14 Failed coupling beams of a 14 storey building in Anchorage 17. 


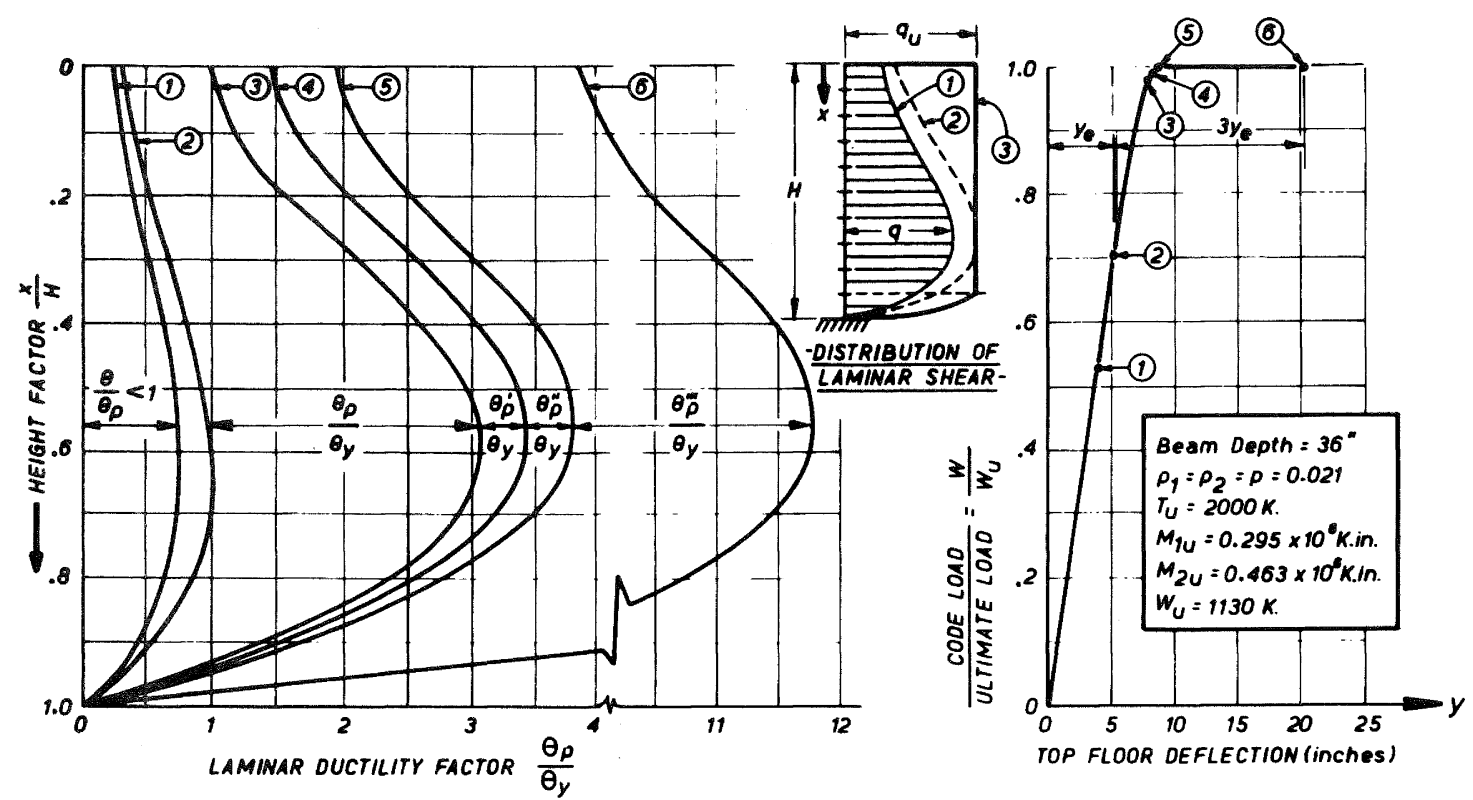

(a) UNIFORM ULTIMATE SHEAR DISTRIBUTION
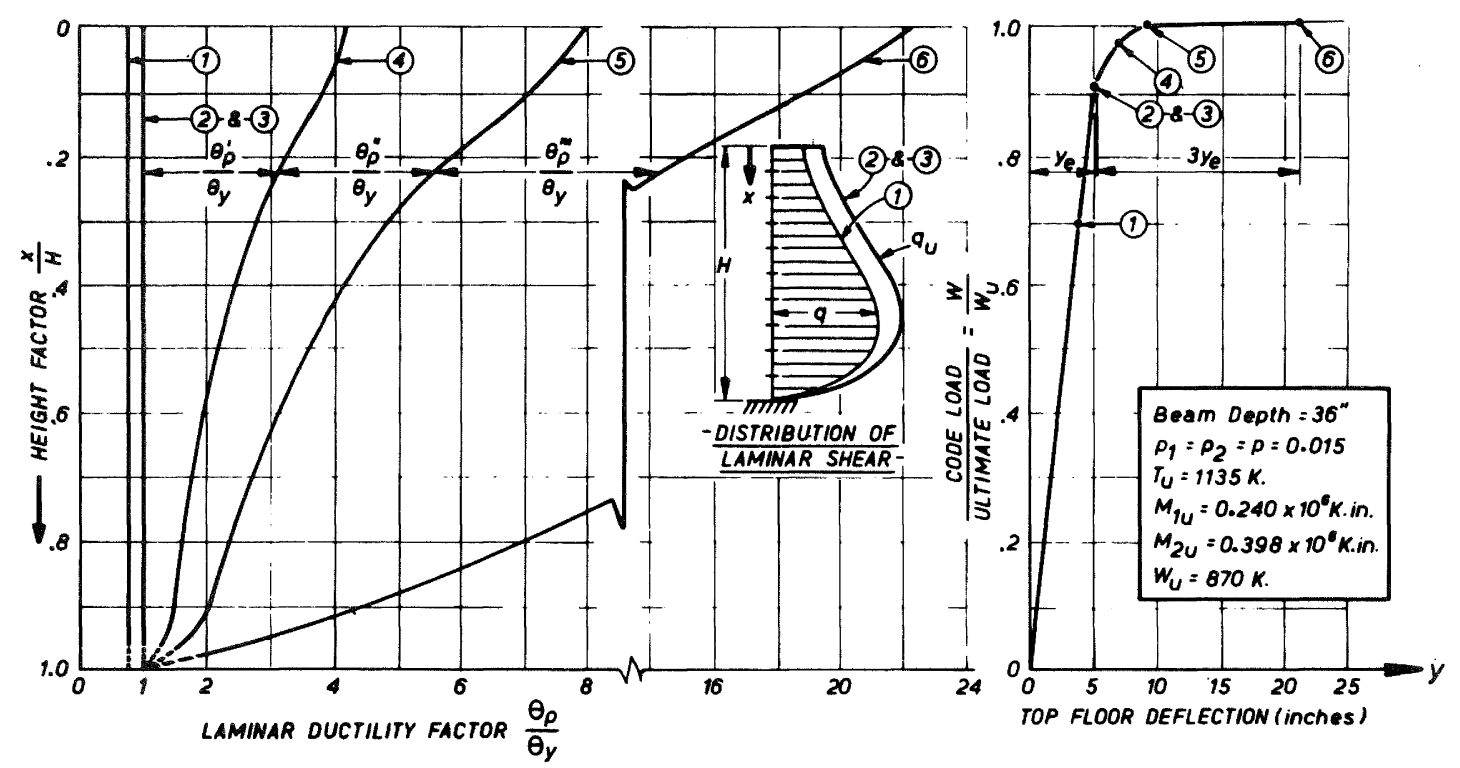

(b) VARIABLE ULTIMATE SHEAR DISTRIBUTION

Fig.15 Laminar shear force distributions, ductility requirements and deflections for a coupled shear wall structure with different distributions of laminar shear strength. 


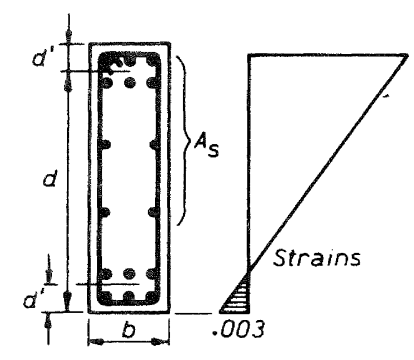

Fig.16 Sectional properties of a typical coupling beam.

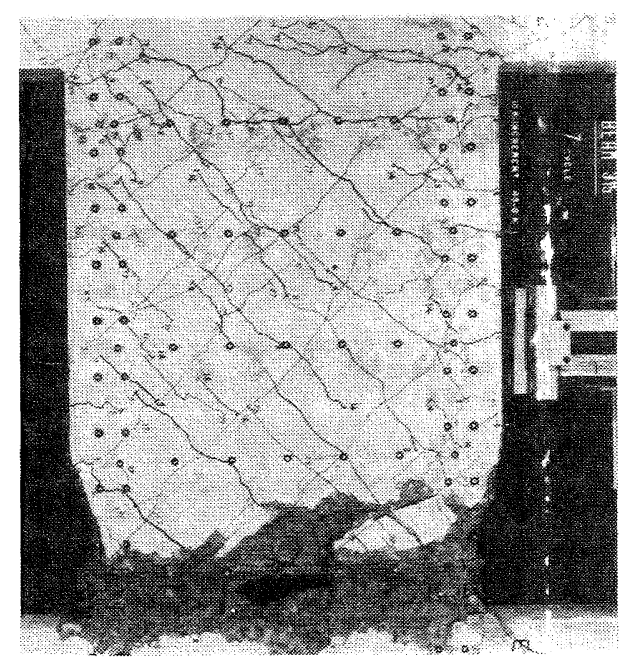

Fig. 17 Sliding shear failure of a coupling beam 22 .
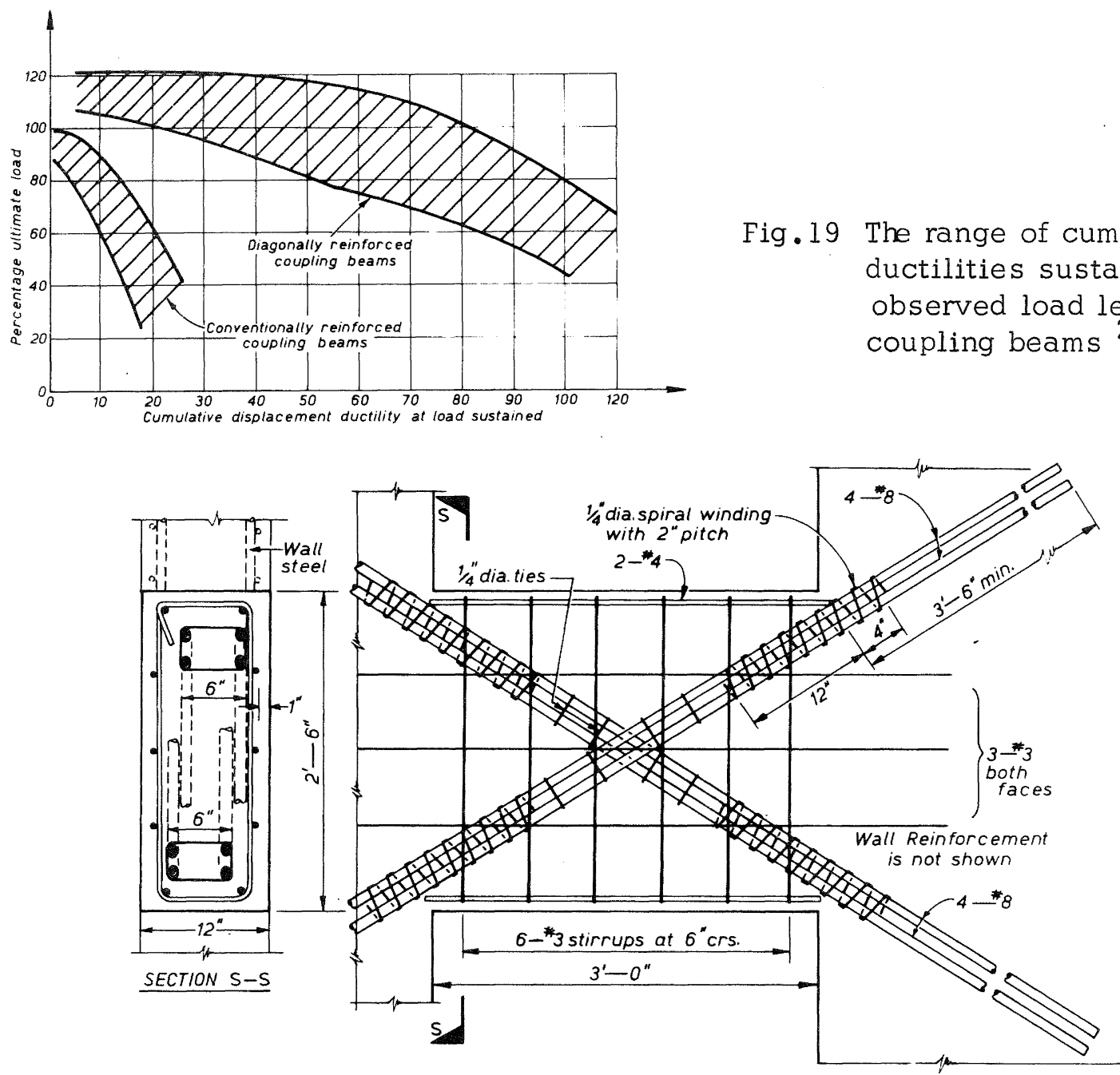

Fig. 18 Prototype of a diagonally reinforced coupling beam.
Fig.19 The range of cumulative ductilities sustained at observed load levels in deep coupling beams 23 . 